\title{
Bright Liver and Alanine Aminotransferase Are Associated with Metabolic Syndrome in Adults
}

\author{
Yung-Hsuan Shen, *** Wei-Shiung Yang, $† \ddagger \$$ Tzong-Hsi Lee,II Long-Teng Lee, ${ }^{*}$ Ching-Yu Chen, ${ }^{*}$ and \\ Kuo-Chin Huang*
}

\begin{abstract}
SHEN, YUNG-HSUAN, WEI-SHIUNG YANG, TZONGHSI LEE, LONG-TENG LEE, CHING-YU CHEN, AND KUO-CHIN HUANG. Bright liver and alanine aminotransferase are associated with metabolic syndrome in adults. Obes Res. 2005;13:1238-1245.

Objectives: The metabolic syndrome has become a significant health problem worldwide. In this study, we investigated the relationship between the metabolic syndrome, bright liver (BL) by ultrasonography (US), and plasma alanine aminotransferase (ALT) levels among apparently healthy adults.

Research Methods and Procedures: A total of 15,430 nonalcoholic healthy adults without hepatitis B or C were recruited from four nationwide MJ Health Screening Centers in Taiwan in 2000. Metabolic syndrome was defined using the National Cholesterol Education Panel (NCEP) metabolic syndrome criteria or modified NCEP criteria. Based on liver US, subjects were classified into either having BL or not. The relationship between the metabolic syndrome, BL, and ALT levels was examined using multivariate logistic regression analysis.
\end{abstract}

Results: The crude OR of the metabolic syndrome was 13.92 (12.19 using modified NCEP criteria), and the ageBMI-sex-adjusted OR was 3.77 (3.71 using modified NCEP criteria) in subjects with BL vs. subjects without BL, respectively. The ORs of the metabolic syndrome were signif-

\footnotetext{
Received for review October 18, 2004 Accepted in final form April 11, 2005

The costs of publication of this article were defrayed, in part, by the payment of page charges. This article must, therefore, be hereby marked "advertisement" in accordance with 18 U.S.C. Section 1734 solely to indicate this fact.

*Department of Family Medicine and $\dagger$ Division of Endocrinology and Metabolism, Department of Internal Medicine, National Taiwan University Hospital, Taipei, Taiwan; $\ddagger$ Graduate Institute of Clinical Medicine, College of Medicine, National Taiwan University, Taipei, Taiwan; §Institute of Biomedical Sciences, Academia Sinica; and IIDivision of Gastroenterology, Department of Internal Medicine, Far Eastern Memorial Hospital, Taipei, Taiwan; **E-DA Hospital, Kaohsiung, Taiwan.

Address correspondence to Kuo-Chin Huang, Department of Family Medicine, National Taiwan University Hospital, 7 Chung-Shan South Road, Taipei, Taiwan 100.

E-mail: chin3@ha.mc.ntu.edu.tw

Copyright $\odot 2005$ NAASO
}

icantly higher in subjects with elevated ALT levels than in those with normal ALT levels. After adjustment for age, sex, and BMI, BL and elevated ALT level were independently associated with increased risk of the metabolic syndrome.

Discussion: Presence of BL and elevated plasma ALT level was independently associated with increased risk of the metabolic syndrome in adults. These factors contribute to a list of well-known risk factors, including obesity, aging, and male sex, and thus can be applied as an additional evaluation for the metabolic syndrome in a clinical setting.

Key words: metabolic syndrome, National Cholesterol Education Panel criteria, bright liver, elevated alanine aminotransferase, waist circumference

\section{Introduction}

The prevalence of obesity has drastically increased in many countries in recent decades $(1,2)$. The metabolic syndrome, a constellation of central obesity, impaired glucose metabolism, dyslipidemia, and hypertension, is associated with subsequent development of type 2 diabetes and cardiovascular diseases (3). Cardiovascular diseases and allcause mortality have also been found to increase in men with the metabolic syndrome, even in the absence of baseline diabetes and cardiovascular diseases (4). Epidemiological data from Europe and the United States suggests that the prevalence of the metabolic syndrome is $\sim 20 \%$ in adults $(5,6)$. In Asians, the prevalence of the metabolic syndrome is $10.2 \%$ in China (7), $12.2 \%$ to $17.9 \%$ in Singapore (8), and $15.2 \%$ to $19.1 \%$ in Korea (9). Therefore, the metabolic syndrome has become a significant health problem worldwide and requires urgent attention in terms of assessing risk factors and clinical management.

Nonalcoholic fatty liver disease (NAFLD) ${ }^{1}$ has been found to have a significant association with insulin resis-

\footnotetext{
${ }^{1}$ Nonstandard abbreviations: NAFLD, nonalcoholic fatty liver disease; ALT, alanine aminotransferase; BL, bright liver; US, ultrasonography; NCEP, National Cholesterol Education Panel.
} 
Table 1. Demographic data, ALT, and prevalence of BL, the metabolic syndrome, and its individual components categorized by sex $(N=15,430)$

\begin{tabular}{|c|c|c|c|c|}
\hline & $\begin{array}{c}\text { Male } \\
(n=7352)\end{array}$ & $\begin{array}{c}\text { Female } \\
(n=8078)\end{array}$ & $\begin{array}{c}\text { Total } \\
(N= \\
15,430)\end{array}$ & $p^{*}$ \\
\hline Age (years) & $37.1 \pm 10.5$ & $36.5 \pm 10.6$ & $36.8 \pm 10.6$ & 0.001 \\
\hline Height $(\mathrm{cm})$ & $170.1 \pm 6.1$ & $157.7 \pm 5.5$ & $163.6 \pm 8.5$ & 0.000 \\
\hline Weight $(\mathrm{kg})$ & $68.3 \pm 10.2$ & $53.7 \pm 8.1$ & $60.7 \pm 11.7$ & 0.000 \\
\hline BMI $\left(\mathrm{kg} / \mathrm{m}^{2}\right)$ & $23.1 \pm 3.1$ & $21.1 \pm 3.2$ & $22.1 \pm 3.3$ & 0.000 \\
\hline $\mathrm{WC}(\mathrm{cm})$ & $80.9 \pm 8.4$ & $69.6 \pm 7.2$ & $74.9 \pm 9.6$ & 0.000 \\
\hline Systolic blood pressure (mm Hg) & $119.7 \pm 14.1$ & $111.4 \pm 15.3$ & $115.4 \pm 15.3$ & 0.000 \\
\hline Diastolic blood pressure $(\mathrm{mm} \mathrm{Hg})$ & $73.2 \pm 10.0$ & $67.2 \pm 10.0$ & $70.1 \pm 10.4$ & 0.000 \\
\hline Fasting glucose $(\mathrm{mM})$ & $5.37 \pm 0.67$ & $5.15 \pm 0.70$ & $5.26 \pm 0.69$ & 0.000 \\
\hline Triglycerides $(\mathrm{mM})$ & $1.53 \pm 1.12$ & $1.02 \pm 0.78$ & $1.27 \pm 0.99$ & 0.000 \\
\hline High-density lipoprotein-cholesterol (mM) & $1.20 \pm 0.30$ & $1.51 \pm 0.35$ & $1.36 \pm 0.36$ & 0.000 \\
\hline ALT (U/liter) & $29.22 \pm 22.87$ & $16.74 \pm 14.03$ & $22.7 \pm 19.8$ & 0.000 \\
\hline Elevated ALT (\%) & 31.5 & 7.0 & 18.7 & 0.000 \\
\hline $\mathrm{BL}(\%)$ & 35.8 & 14.7 & 24.8 & 0.000 \\
\hline Metabolic syndrome (\%) & 17.6 & 3.3 & 10.1 & 0.000 \\
\hline Metabolic syndrome2 $(\%) \dagger$ & 29.2 & 4.8 & 16.4 & 0.000 \\
\hline Central obesity $(\%)$ & 15.5 & 1.6 & 8.2 & 0.000 \\
\hline Central obesity2 $(\%) \dagger$ & 47.9 & 7.3 & 26.7 & 0.000 \\
\hline High blood pressure $(\%)$ & 27.5 & 13.2 & 20.2 & 0.000 \\
\hline High fasting glucose (\%) & 6.1 & 3.5 & 4.8 & 0.000 \\
\hline High triglycerides $(\%)$ & 29.8 & 9.4 & 19.1 & 0.000 \\
\hline Low high-density lipoprotein-cholesterol (\%) & 67.7 & 29.9 & 47.9 & 0.000 \\
\hline
\end{tabular}

tance and metabolic syndrome disorders (10-12). This disease is characterized by a wide spectrum of liver damage, ranging from simple steatosis to steatohepatitis and cirrhosis (13-15). Depending on different methodologies, the prevalence of NAFLD is $2.8 \%$ to $30.3 \%$ in the general population (16-18). The prevalence of NAFLD is associated with increments of BMI $(18,19)$, because steatosis was observed in $86 \%$ of severely obese patients (20). Thus, the presence of NAFLD is being recognized as a common liver disorder in patients presenting with the metabolic syndrome.

Alanine aminotransferase (ALT) is a liver-specific enzyme, and thus, it is an indicator of liver injury. Elevated plasma ALT levels are associated with obesity and the metabolic syndrome (16,21-23). However, in these studies, elevated ALT levels were only a surrogate of NAFLD, and neither image study nor biopsy of liver was used. In this study, we investigated the relationship between the metabolic syndrome, bright liver (BL) by liver ultrasonography (US), and plasma ALT levels in a large adult population.

\section{Research Methods and Procedures}

\section{Subjects and Measurements}

The data were collected from four private, nationwide MJ Health Screening Centers in Taiwan from January 2000 to December 2000. The centers provide a multidisciplinary team approach for their members, with the annual health assessment by registered health practitioners. All subject data were recorded using standardized data sheets and were entered into a database. The demographic profiles of the Taiwanese adults that attend the health centers are similar to those of the general Taiwanese population (24). A total of 15,430 healthy adults of a total of 79,852 subjects $(38,807$ men and 41,045 women) were recruited in this study. They denied any history of major systemic diseases such as chronic liver disease, diabetes, hypertension or hyperlipidemia, or autoimmune diseases, and they were not taking any medication known to cause or promote fatty liver disease or plasma ALT level elevation. Subjects positive for hepatitis 

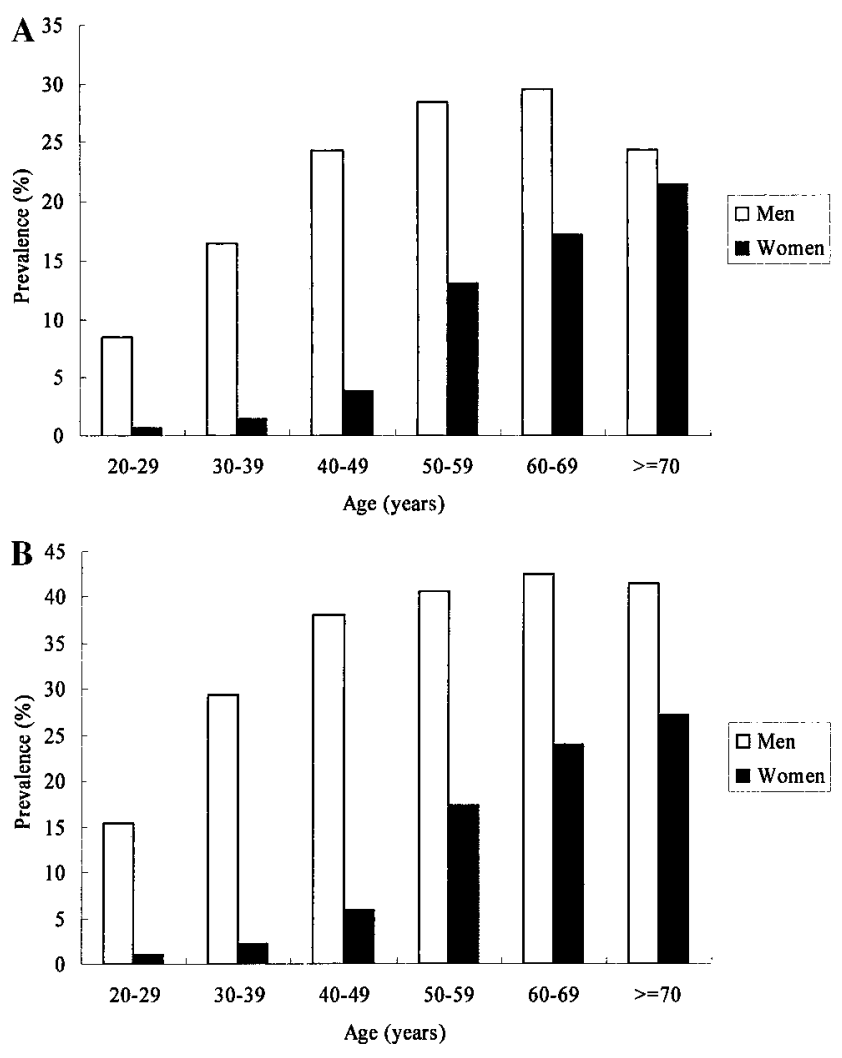

Figure 1: Prevalence of the metabolic syndrome using (A) NCEP criteria and (B) modified NCEP criteria (central obesity, WC $>90$ $\mathrm{cm}$ in men and $>80 \mathrm{~cm}$ in women) stratified by age group and sex.

B surface antigen $(16.0 \%$ in all, $18.9 \%$ in men and $13.2 \%$ in women) or antibody to hepatitis $\mathrm{C}$ virus (2.9\% in all, $2.7 \%$ in men and $3.2 \%$ in women) were excluded. Subjects having a history of current or past excessive alcohol drinking as defined by an average daily consumption of alcohol $>20$ grams (from a questionnaire; $2.1 \%$ in all, $3.6 \%$ in men and $0.7 \%$ in women) were also excluded. The anthropometric characteristics were measured and described in Huang et al. (25). BMI was calculated as weight (kilograms) divided by height (meters squared). Blood pressure was measured in the right arm using an appropriately sized cuff and a standard mercury sphygmomanometer while subjects were in a sitting position. A venous blood sample was taken after an 8-hour fast. Plasma ALT, glucose, and lipids were measured using a Hitachi 7150 (Tokyo, Japan). The metabolic syndrome was defined clinically, based on the presence of three or more of the following National Cholesterol Education Panel (NCEP) criteria (26): 1) central obesity [waist circumference (WC) $>102 \mathrm{~cm}$ in men and $>88 \mathrm{~cm}$ in women], 2) a high triglyceride level $(\geq 1.69 \mathrm{mM}), 3)$ a low highdensity lipoprotein cholesterol level $(<1.03 \mathrm{mM}$ for men and $<1.29 \mathrm{mM}$ for women), 4) high blood pressure $(\geq 130 / 85 \mathrm{~mm} \mathrm{Hg}), 5)$ a high fasting plasma glucose concentration $(\geq 6.1 \mathrm{mM})$. Furthermore, the modified NCEP

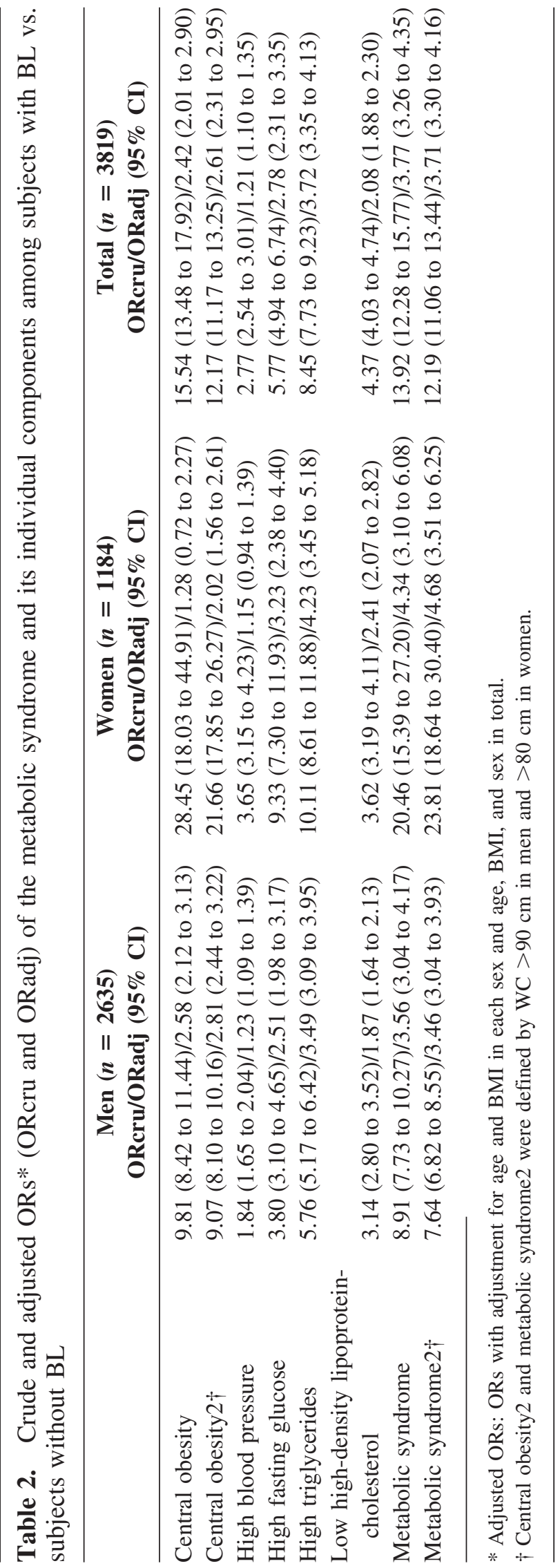




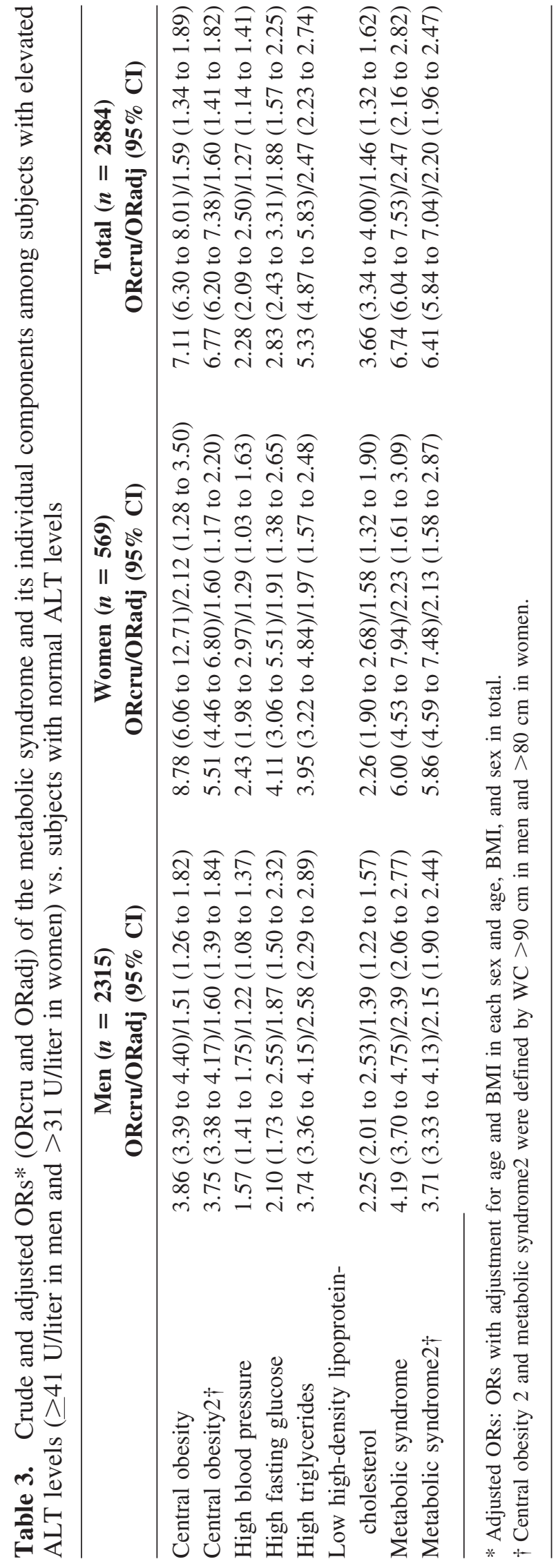

criteria using a lower WC cut-off (WC $>90 \mathrm{~cm}$ in men and $>80 \mathrm{~cm}$ in women) was also applied for comparison because of a different definition of central obesity in this population $(8,27)$. Liver US scanning was performed by qualified physicians to assess hepatic steatosis $(28,29)$; the subjects were divided into two groups, i.e., with and without BL. Ethics approval for patient recruitment and analyzing the data was obtained from the MJ Research Foundation Review Committee in Taiwan.

\section{Statistical Analysis}

Data were expressed as the mean \pm SD for continuous variables. Student's $t$ test for unpaired data were used for the comparison of mean values between sexes. Proportions and categorical variables were tested by the $\chi^{2}$ test and by the two-tailed Fisher's exact method when appropriate. ORs of having the metabolic syndrome and its individual components among subjects with BL or elevated ALT levels vs. subjects without BL or elevated ALT levels were calculated with and without adjustment for age and BMI in each sex. A multivariate logistic regression analysis categorized by sex was performed with the metabolic syndrome as the outcome variable, and age, BMI, BL, and ALT level as independent variables. ALT level was defined as normal $(<41 \mathrm{U} /$ liter in men and $<31 \mathrm{U} /$ liter in women), mild (1-fold) elevation (41 to $80 \mathrm{U} /$ liter in men and 31 to 60 U/liter in women), moderate (2-fold) elevation (81 to 120 U/liter in men and 61 to $90 \mathrm{U} /$ liter in women), and severe ( $>3$-fold) elevation (>121 U/liter in men and $>91 \mathrm{U} /$ liter in women). These statistical analyses were performed using the PC version of SPSS statistical software (11th version; SPSS, Chicago, IL).

\section{Results}

The prevalence of the metabolic syndrome was $10.1 \%$ ( $16.4 \%$ using modified NCEP criteria). It was $\sim 17.6 \%$ (29.2\% using modified NCEP criteria) in men and 3.3\% (4.8\% using modified NCEP criteria) in women, respectively (Table 1). Men had a higher prevalence of the metabolic syndrome and its individual components than women. The prevalence of the metabolic syndrome increased with age in each sex (Figure 1; test for trend, $p<$ 0.001). The prevalence of individual components of the metabolic syndrome is also listed in Table 1. Among these, low high-density lipoprotein-cholesterol was the highest (47.9\%), and high fasting glucose was the lowest (4.8\%). The prevalence of BL and elevated ALT levels was 24.8\% and $18.7 \%$, respectively. The means of the demographic data were statistically different between men and women. Plasma ALT levels were higher in men $(29.22 \pm 22.87$ U/liter) than in women (16.74 $\pm 14.03 \mathrm{U} /$ liter).

The crude and adjusted ORs of having the metabolic syndrome and its individual components were significantly 
Table 4. ORs $(95 \% \mathrm{CI})$ of having the metabolic syndrome derived from a multivariate logistic regression analysis categorized by sex using age, BMI, BL, and ALT groups as independent variables

\begin{tabular}{|c|c|c|c|c|}
\hline \multirow[b]{2}{*}{ Variables } & \multicolumn{2}{|c|}{ Model 1* } & \multicolumn{2}{|c|}{ Model 2* } \\
\hline & $\begin{array}{l}\text { Men ORs } \\
(95 \% \text { CI })\end{array}$ & $\begin{array}{c}\text { Women ORs } \\
(95 \% \text { CI })\end{array}$ & $\begin{array}{l}\text { Men ORs } \\
(95 \% \text { CI })\end{array}$ & $\begin{array}{c}\text { Women ORs } \\
(95 \% \text { CI })\end{array}$ \\
\hline Age (years) & 1.05 (1.04 to 1.05$)$ & 1.07 (1.06 to 1.08$)$ & 1.04 (1.03 to 1.04$)$ & 1.07 (1.06 to 1.08$)$ \\
\hline BMI $\left(\mathrm{kg} / \mathrm{m}^{2}\right)$ & 1.39 (1.35 to 1.44$)$ & 1.27 (1.22 to 1.33$)$ & 1.33 (1.30 to 1.37$)$ & 1.34 (1.28 to 1.39$)$ \\
\hline \multicolumn{5}{|l|}{ BL } \\
\hline No & 1 (reference) & 1 (reference) & 1 (reference) & 1 (reference) \\
\hline Yes & 3.05 (2.59 to 3.60$)$ & 4.06 (2.88 to 5.72$)$ & 3.06 (2.68 to 3.48$)$ & 4.40 (3.28 to 5.91$)$ \\
\hline \multicolumn{5}{|l|}{ ALT groups $\dagger$} \\
\hline Normal & 1 (reference) & 1 (reference) & 1 (reference) & 1 (reference) \\
\hline Mild & 1.77 (1.50 to 2.08 ) & 1.58 (1.10 to 2.27$)$ & 1.61 (1.40 to 1.84$)$ & 1.48 (1.06 to 2.06$)$ \\
\hline Moderate & 2.26 (1.70 to 2.99$)$ & 2.47 (1.15 to 5.28$)$ & 2.01 (1.53 to 2.62$)$ & 2.67 (1.31 to 5.44$)$ \\
\hline Severe & 2.36 (1.58 to 3.51$)$ & 2.58 (1.0 to 6.70$)$ & 1.82 (1.22 to 2.70$)$ & 1.70 (0.67 to 4.34$)$ \\
\hline
\end{tabular}

\footnotetext{
* Metabolic syndrome was defined by the NCEP criteria in Model 1 and by the modified NCEP criteria using WC $>90 \mathrm{~cm}$ in men and $>80$ $\mathrm{cm}$ in women in Model 2.

$\dagger$ ALT was defined as normal ( $<41 \mathrm{U} /$ liter in men and $<31 \mathrm{U} /$ liter in women), mild elevation (41 to $80 \mathrm{U} /$ liter in men and 31 to $60 \mathrm{U} /$ liter in women), moderate elevation (81 to $120 \mathrm{U} /$ liter in men and 61 to $90 \mathrm{U} / \mathrm{liter}$ in women), and severe elevation ( $\geq 121 \mathrm{U} / \mathrm{liter}$ in men and $\geq 91 \mathrm{U} /$ liter in women).
}

higher in subjects with BL than in those without BL $(\mathrm{OR}>$ $1, p<0.05$ in each analysis; Table 2). The crude OR of the metabolic syndrome was 13.92 (12.19 using modified NCEP criteria), and the adjusted OR was 3.77 (3.71 using modified NCEP criteria) in subjects with BL vs. subjects without BL. Similarly, the crude and adjusted ORs of having the metabolic syndrome and its individual components were significantly higher in subjects with elevated ALT levels than in those with normal ALT levels (OR $>1, p<$ 0.05 in each analysis; Table 3 ). The crude OR of the metabolic syndrome was 6.74 (6.41 using modified NCEP criteria), and the adjusted OR was 2.47 (2.20 using modified NCEP criteria) in subjects with elevated ALT levels vs. subjects with normal ALT levels.

Using a multivariate logistic regression analysis with the metabolic syndrome as the outcome variable, we found that age, BMI, BL, and ALT level were independent variables associated with the metabolic syndrome in these subjects (Table 4). With increasing age and BMI, the ORs of having the metabolic syndrome increased significantly in each sex. There was no statistically significant difference in the ORs of having the metabolic syndrome between men and women with BL, which were 3.05 (95\% CI of OR $=2.59$ to 3.60$)$ and 4.06 (95\% CI of OR $=2.88$ to 5.72$)$ in Model 1 and $3.06(95 \% \mathrm{CI}$ of $\mathrm{OR}=2.68$ to 3.48$)$ and $4.40(95 \% \mathrm{CI}$ of $\mathrm{OR}=3.28$ to 5.91 ) in Model 2. Furthermore, we found that, compared with the subjects with normal ALT levels, the subjects with elevation of ALT levels had higher ORs of having the metabolic syndrome in men and women in Model 1 and Model 2. However, there was no statistically significant difference among the three groups of ALT elevation. Moreover, compared with subjects with normal ALT level and without BL, ORs of having the metabolic syndrome in subjects with BL and elevated ALT levels were 5.84 (95\% $\mathrm{CI}=4.75$ to $7.16 ; 5.11,95 \% \mathrm{CI}=4.34$ to 6.03 using modified NCEP criteria) in men and 6.99 (95\% CI = 4.50 to $10.86 ; 7.04,95 \% \mathrm{CI}=4.76$ to 10.41 using modified NCEP criteria) in women, with adjustment for age and BMI (Table 5).

\section{Discussion}

In this study, we found that the metabolic syndrome was more common among previously healthy adults with BL, based on liver US, compared with subjects without BL. We also found that the ORs of having the metabolic syndrome were higher in subjects with elevated ALT levels than those with normal ALT levels. Furthermore, we showed, for the first time, that BL and elevated ALT level were independently related to the risk of having the metabolic syndrome after adjustment for age, sex, and BMI.

It has been recognized that NAFLD is closely associated with insulin resistance, which commonly occurs in obese subjects and in people with the metabolic syndrome (1012,30). However, Marchesini et al. (31) found that NAFLD was also associated with insulin resistance in lean subjects 


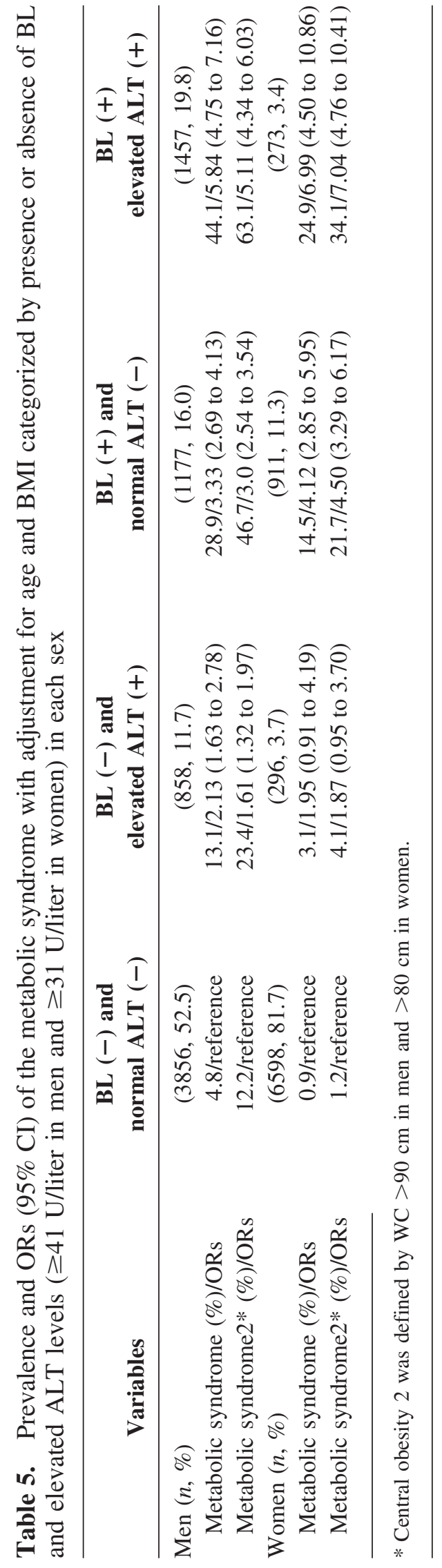

with normal glucose tolerance. Therefore, insulin resistance may play a central role in the accumulation of triglycerides within the hepatocytes and also probably in the initiation of the inflammatory cascade, causing hepatocyte injury. For example, unexplained ALT level elevation was strongly associated with adiposity and other features of the metabolic syndrome including high hypertriglycerides and fasting insulin and lower high-density lipoprotein levels (19). Hyperinsulinemia and hyperleptinemia have been found to be the major determinants of the association of overweight with elevated ALT level (16). Furthermore, Torgerson et al. (21) have also shown that ALT is independently related to serum insulin levels in women with a BMI of 26.7 to $68 \mathrm{~kg} / \mathrm{m}^{2}$. Interestingly, higher ALT levels have been noted to correlate with obesity and insulin resistance and can independently predict the incidence of diabetes in 451 nondiabetic Pima Indians (22). In this study, we found that the crude and adjusted ORs of the metabolic syndrome were significantly higher in subjects with BL than in those without BL (Table 2 ), and they were also significantly higher in subjects with elevated ALT levels than in those with normal ALT levels (Table 3). Therefore, our results support that NAFLD is independently associated with the metabolic syndrome, and it is also implicated that NAFLD could be regarded as the hepatic manifestation of the metabolic syndrome.

Although liver biopsy is the gold standard to differentiate innocent steatosis from progressive steatohepatitis, liver US is a useful tool in clinical practice and epidemiological studies for logistic and ethical reasons. In addition, liver US has a good correlation with the histological findings of fatty infiltration (29,32). However, Saadeh et al. (33) have shown that the presence of $>33 \%$ fat on liver biopsy is optimal for detecting steatosis by radiological imaging, including US, computerized tomography, and magnetic resonance imaging. In addition, Mofrad et al. (34) have shown that the entire histological spectrum of NAFLD can be seen in individuals with normal ALT levels, and the histologic spectrum in these individuals is not significantly different from those with elevated ALT levels. In this study, we found that $54.7 \%$ of subjects with BL had normal ALT levels, and $40 \%$ of subjects with elevated ALT levels had no evidence of BL (calculated from Table 5). Thus, we chose ALT level to be another indicator of "liver health" in addition to liver US in this study. Surprisingly, we noted that BL and elevated ALT levels were independently associated with the risk of having the metabolic syndrome (Tables 4 and 5).

The prevalence of the metabolic syndrome varies between people in Western countries and Asians (5-9). The definition of central obesity using WC in NCEP criteria for the metabolic syndrome may not be appropriate for Asians $(8,27)$, which may underestimate the population at risk. Previously, we have also shown that, at lower BMIs and WCs, increased risk of having obesity-related cardiovascu- 
lar risk factors was found in Taiwanese adults $(25,35)$. Thereby, with a lower WC cut-off (WC $>90 \mathrm{~cm}$ in men and $>80 \mathrm{~cm}$ in women), the prevalence of the metabolic syndrome increased from $10.1 \%$ to $16.4 \%$ in this study. Similarly, the prevalence of the metabolic syndrome in Singapore increased from $12.2 \%$ to $17.9 \%$ (8). Interestingly, the relationship between BL, ALT, and the metabolic syndrome didn't change when using the modified NCEP criteria in this study. Taken together, it seemed appropriate to use a lower WC cut-off in defining the metabolic syndrome in Taiwan.

In summary, we found that subjects with BL by US were associated with higher risk of having the metabolic syndrome compared with subjects without BL. We also showed that elevated plasma ALT level was independently related to the risk of having the metabolic syndrome after adjustment for BL, age, sex, and BMI. Therefore, BL by US and plasma ALT levels can be applied as an additional evaluation for the metabolic syndrome in a clinical setting. Although our study was limited by the cross-sectional design, and there was potential bias for the participation by the subjects, our results suggested that NAFLD should be regarded as the hepatic manifestation of the metabolic syndrome. The interplay between liver and the metabolic syndrome merits further study.

\section{Acknowledgments}

The authors thank Dr. Ruby Lin (Ramaciotti Center for Gene Function Analysis, School of Biotechnology and Biomolecular Sciences, University of New South Wales, Sydney, Australia) for kindly reviewing the manuscript and Liu I-Lin for technical assistance. There was no funding/outside support for this study.

\section{References}

1. James PT, Leach R, Kalamara E, Shayeghi M. The worldwide obesity epidemic. Obes Res. 2001;9:228S-33S.

2. Flegal KM, Carroll MD, Ogden CL, Johnson CL. Prevalence and trends in obesity among US adults, 1999-2000. JAMA. 2002;288:1723-7.

3. Haffner SM, Valdez RA, Hazuda HP, Mitchell BD, Morales PA, Stern MP. Prospective analysis of the insulinresistance syndrome (syndrome X). Diabetes. 1992;41:71522.

4. Lakka HM, Laaksonen DE, Lakka TA, et al. The metabolic syndrome and total and cardiovascular disease mortality in middle-aged men. JAMA. 2002;288:2709-16.

5. Ford ES, Giles WH, Dietz WH. Prevalence of the metabolic syndrome among US adults: findings from the third National Health and Nutrition Examination Survey. JAMA. 2002;287: $356-9$.

6. Panagiotakos DB, Pitsavos C, Chrysohoou C, et al. Impact of lifestyle habits on the prevalence of the metabolic syndrome among Greek adults from the ATTICA study. Am Heart J. 2004; 147:106-12.
7. Jia WP, Xiang KS, Chen L, Lu JX, Wu YM. Epidemiological study on obesity and its comorbidities in urban Chinese older than 20 years of age in Shanghai, China. Obes Rev. 2002;3:157-65.

8. Tan CE, Ma S, Wai D, Chew SK, Tai ES. Can we apply the National Cholesterol Education Program Adult Treatment Panel definition of the metabolic syndrome to Asians? Diabetes Care. 2004;27:1182-6.

9. Park HS, Oh SW, Cho SI, Choi WH, Kim YS. The metabolic syndrome and associated lifestyle factors among South Korean adults. Int J Epidemiol. 2004;33:328-36.

10. Marchesini G, Brizi M, Bianchi G, et al. Nonalcoholic fatty liver disease: a feature of the metabolic syndrome. Diabetes. 2001;50:1844-50.

11. Pagano G, Pacini G, Musso G, et al. Nonalcoholic steatohepatitis, insulin resistance, and metabolic syndrome: further evidence for an etiologic association. Hepatology. 2002;35: $367-72$.

12. Marchesini G, Bugianesi E, Forlani G, et al. Nonalcoholic fatty liver, steatohepatitis, and the metabolic syndrome. Hepatology. 2003;37:917-23.

13. Sheth SG, Gordon FD, Chopra S. Nonalcoholic steatohepatittis. Ann Intern Med. 1997;126:137-45.

14. Angelico F, Del Ben M, Conti R, et al. Non-alcoholic fatty liver syndrome: a hepatic consequence of common metabolic diseases. J Gastroenterol Hepatol. 2003;18:588-94.

15. Falck-Ytter Y, Younossi ZM, Marchesini G, McCullough AJ. Clinical features and natural history of nonalcoholic steatosis syndromes. Semin Liver Dis. 2001;21:17-26.

16. Ruhl CE, Everhart JE. Determinants of the association of overweight with elevated serum alanine aminotransferase activity in the United States. Gastroenterology. 2003;124:71-9.

17. Bellentani S, Saccoccio G, Masutti F, et al. Prevalence of and risk factors for hepatic steatosis in Northern Italy. Ann Intern Med. 2000;132:112-7.

18. Kojima S, Watanabe N, Numata M, Ogawa T, Matsuzaki S. Increase in the prevalence of fatty liver in Japan over the past 12 years: analysis of clinical background. J Gastroenterol. 2003;38:954-64.

19. Clark JM, Brancati FL, Diehl AM. The prevalence and etiology of elevated aminotransferase levels in the United States. Am J Gastroenterol. 2003;98:960-7.

20. Marceau P, Biron S, Hould FS, et al. Liver pathology and the metabolic syndrome $\mathrm{X}$ in severe obesity. J Clin Endocrinol Metab. 1999;84:1513-7.

21. Torgerson JS, Lindroos AK, Sjöström CD, Olsson R, Lissner L, Sjöström L. Are elevated aminotransferases and decreased bilirubin additional characteristics of the metabolic syndrome? Obes Res. 1997;5:105-14.

22. Vozarova BSN, Lindsay RS, Saremi A, Pratley RE, Bogardus C, Tataranni PA. High alanine aminotransferase is associated with decreased hepatic insulin sensitivity and predicts the development of type 2 diabetes. Diabetes. 2002;51: 1889-95.

23. Nakanishi N, Suzuki K, Tatara K. Serum gamma-glutamyltransferase and risk of metabolic syndrome and type 2 diabetes in middle-aged Japanese men. Diabetes Care. 2004;27:142732. 
24. Department of Health. Taiwan Public Health Report 2000. Taipei, Taiwan: Department of Health; 2002.

25. Huang KC, Lin WY, Lee LT, et al. Four anthropometric indices and cardiovascular risk factors in Taiwan. Int J Obes Relat Metab Disord. 2002;26:1060-8.

26. Expert Panel on Detection, Evaluation, and Treatment of High Blood Cholesterol in Adults. Executive Summary of The Third Report of The National Cholesterol Education Program (NCEP) Expert Panel on Detection, Evaluation, And Treatment of High Blood Cholesterol In Adults (Adult Treatment Panel III). JAMA. 2001;285:2486-97.

27. WHO Expert Panel. Appropriate body mass index for Asian populations and its implications for policy and intervention strategies. Lancet. 2004;363:157-63.

28. Quinn SF, Gosink BB. Characteristic sonographic signs of hepatic fatty infiltration. AJR Am J Roentgenol. 1985;145: 753-55.

29. Saverymuttu SH, Joseph AE, Maxwell JD. Ultrasound scanning in the detection of hepatic fibrosis and steatosis. $\mathrm{Br}$ Med J. 1986;292:13-5.
30. Festi D, Colecchia A, Sacco T, Bondi M, Roda E, Marchesini G. Hepatic steatosis in obese patients: clinical aspects and prognostic significance. Obes Rev. 2004;5:27-42.

31. Marchesini G, Brizi M, Morselli-Labate AM, et al. Association of nonalcoholic fatty liver disease with insulin resistance. Am J Med. 1999;107:450-5.

32. Joseph AE, Saverymuttu SH, al-Sam S, Cook MG, Maxwell JD. Comparison of liver histology with ultrasonography in assessing diffuse parenchymal liver disease. Clin Radiol. 1991;43:26-31.

33. Saadeh S, Younossi ZM, Remer EM, et al. The utility of radiological imaging in nonalcoholic fatty liver disease. Gastroenterology. 2002;123:745-50.

34. Mofrad P, Contos MJ, Haque M, et al. Clinical and histologic spectrum of nonalcoholic fatty liver disease associated with normal ALT values. Hepatology. 2003;37:1286-92.

35. Lin WY, Lee LT, Chen CY, et al. Optimal cut-off values for obesity: using simple anthropometric indices to predict cardiovascular risk factors in Taiwan. Int J Obes Relat Metab Disord. 2002;26:1232-8. 